\title{
Estudo de métodos de reconhecimento de signos utilizados por designers de moda
}

\section{Study of signs recognition methods used by fashion designers}

\author{
Emanuella Scoz $^{[1]}$, Elton Moura Nickel ${ }^{[2]}$, Flavio Anthero \\ Nunes Viana dos Santos ${ }^{[3]}$
}

\begin{abstract}
Resumo: No processo do design, durante o desenvolvimento de produtos, o designer pesquisa e interpreta informações diversas do consumidor, mercado, produto, dentre outros, que adentram questões subjetivas, como signos, que surgem das interações sociais e com produto. O objetivo dessa pesquisa foi identificar a existência e uso de métodos de reconhecimento dos signos atribuídos ao vestuário. Os dados apresentados foram gerados por um questionário aplicado a cinco profissionais, de diferentes locais de Santa Catarina, de diferentes profissões criativas de moda, aos dados aplicou-se análise documental de Bardin (2016). Com os resultados obtidos nessa pesquisa não foi possível identificar um método específico para reconhecimento de signos atribuídos aos produtos do vestuário. Em lugar deste, é utilizado método de desenvolvimento de produtos, que atribui uma forma subjetiva de compreender signos.
\end{abstract}

Palavras-chave: Design de moda. Método. Signo.

Abstract: In the design process, during product development, the designer researches and interprets different information about the consumer, market, product, among others, which enter into subjective issues, such as signs, which arise from social interactions and with the product. The objective of this research was to identify the existence and use of methods for recognizing the signs identified in clothing. The data provided was generated by one applied to five professionals, from different locations in Santa

[1] Doutoranda em Design, UDESC.manuh.scoz@gmail.com

[2] Doutor em Engenharia de Produção, UFSC. elton.nickel@gmail.com

[3] Doutor em Engenharia de Produção, UFSC. flavio.santos@udesc.br 
Catarina, from different creative fashion professions, and the document analysis of Bardin (2016) was applied to the data. With the results obtained in this research, it was not possible to identify a specific method for the recognition of signs identified in clothing products. Instead, the product development method is used, which provides a way of understanding the signs.

Keywords: Fashion design. Method. Sign.

\section{INTRODUÇÃO}

O sistema de significação se processa de forma cognitiva, sendo estudo do design por representar a interação de indivíduos com os artefatos, é o que Löbach (2001, p.24) chama de "relações objetualizadas", em que os objetos são utilizados como meio de transporte de informações. Para Sant'Anna (2016), os objetos do vestuário recebem significado, o que os torna uma parte importante do estudo da moda. Para Scoz et al. (2019), a roupa, como um utensílio, é um objeto do cotidiano que vem sendo significado ao longo dos séculos, mesmo antes do surgimento do termo moda, recebendo signos que referenciam uma relação do ser humano com esses objetos ainda mais representativa, pois é proveniente de suas ações básicas, das ocupações laborais e do reconhecimento das diferenças de gênero nas sociedades, por exemplo.

O processo de significação é trazido por Hall (2016), como algo fundamental para a incorporação dos significados em determinada cultura, ocorrendo por meio da linguagem, dentre as quais, a linguagem semiótica da moda, no reconhecimento que outros indivíduos dão aos signos atribuídos por outrem.

Para Oliveira (2007), a leitura das produções de moda ocorre como uma espécie de texto visual. As imagens do Design expressam ideias, conceitos e noções a partir de elementos constitutivos, como cores, formas, texturas, materiais, aviamentos, cortes, caimentos, localização, tamanhos etc. A leitura deles nos artefatos, e de seus atributos culturais, faz parte do trabaIho de pesquisa e criação do designer, podendo ser considerada uma parte do desenvolvimento de produtos em que se processam, cognitivamente, informações subjetivas da pesquisa com o consumidor, mercado, produtos, famílias do design etc. 
Para Mukarovski (2000), o significado é atribuído ao produto no momento da compra, de forma que a valoração estética atribuído aos elementos que compõem a forma necessitam estar claras, para que flua comunicação entre o objeto e o consumidor. É da escolha e interpretação do designer que dependerá a assertividade na comunicação do produto com consumidor, a partir das significações dadas aos produtos desenvolvidos, por meio dos atributos estéticos e semânticos escolhidos.

Mukarovski (2000), dá atenção especial a moda, que diz exercer uma influência niveladora sobre a norma que fundamenta a função estética, agindo sobre diversas normas paralelas em função de uma única. Santaella e Nöth (2009), atribuem isso ao sistema das mercadorias que, pela produção em massa, padroniza a estética. No design de moda, o valor estético posiciona-se centrado no usuário, seguindo períodos ou estilos e aplicando normas, porque o valor estético segue uma norma.

Barthes (1981, p.79), ao estudar "a estrutura dos objetos sociais, das imagens culturais, dos estereótipos, tanto nas sociedades arcaicas como em nossas sociedades modernas tecnicistas" voltou olhar sobre a moda, como uma maneira de vestir, colocando os artigos do vestuário na gama de objetos que são veículos de signos. E, mesmo indicando a moda como algo que se exprime no coletivo, definiu que a roupa descreve o que os indivíduos querem exprimir de si. Para Scoz et al. (2019, [s.p.]), “O processo criativo de uma Roupa é complexo e envolve uma série de valores, ele é ligado ao espírito humano, pois, este cria uma imagem para representar e se envolver com objetos de profundo significado particular".

O consumidor, no entanto, é perpassado pela cultura, assim é que, pelos movimentos sociais, determinados signos surgem, são criados e recriados, ocorrem a partir de signos de movimentos anteriores e serão repassados por meio da linguagem da moda. Ainda, a psicologia da gestalt, e conceitos de estética da filosofia clássica, permitem analisar a ação de determinados elementos constituintes dos objetos, no cognitivo 
humano. Dessa forma, é possível observar que cores claras, tons pastéis, formas arredondadas, silhuetas justas, motivos florais, comumente, indicam uma aura feminina ao produto, por fazer parte de uma elaboração cultural anterior, que vigorou por séculos. Enquanto cores fortes, matizes puras, traços largos, formas grandes, geométricos duros, e motivos desordenados atribuem aos objetos certo grau de agressividade, por estar relacionado a assimetria e dureza (GOMES FILHO, 2008).

No que concerne aos signos atribuídos pelo consumidor aos artefatos, no entanto, exige-se uma pesquisa profunda do designer a respeito da relação ser humano objeto, no contexto de vida do usuário. Para Norman (2006), o mapeamento do usuário é a forma de determinar o relacionamento dele com o produto. Mapeiam-se: as intenções, possíveis ações do usuário, as ações e seus efeitos sobre o sistema, o verdadeiro estado do sistema e o que é perceptível pela visão, som ou toque, o estado percebido e as necessidades, intenções e expectativas do usuário.

Para a compreensão dos fatores estéticos do produto para o consumidor, a gestalt (GOMES FILHO, 2008; STERNBERG, 2010), aponta que o objeto é compreendido a partir da interação dos significados atribuídos a cada um dos elementos da imagem, de maneira tal que, para que o designer compreenda um signo, Gomes Filho (2008), Greimas (1984), e Oliveira (2007), apontaram a necessidade de ele analisar os referenciais semânticos do objeto separadamente, e então a relação entre eles.

Como referenciais semânticos, são compreendidos os elementos que constituem um objeto, as linhas, traços, materiais, aviamentos, cores, localização, tamanho, ângulo, texturas dentre outros, e os significados dados, pelo consumidor, a eles. 0 signo, segundo Greimas (1984), é mutável, porque segue as construções culturais. A partir de Heskett (2002), compreendeu-se que a semântica pode se beneficiar da semiótica, ao considerar que um signo é sempre seu significado oposto, sendo possível encontrar num mesmo estudo, os signos e seus 
opostos, categorias de signos e seus opostos, podendo se referir às relações de consumo opostas a estudada. Para Greimas (1984, p.41), "a interpretação [...] consiste em compará-los e em opô-los uns aos outros, elaborando, em última instância, um sistema de significados paralelo e coextensivo ao sistema de símbolos que se está tentando descrever". Assim, apesar de não ser possível determinar um signo sem uma pesquisa com o consumidor, a partir de determinados signos pode-se encontrar significados contrários, formando uma rede de categorias de sentido. Assim como, a partir de um signo, pode-se relacionar atribuições de sentido posteriores, e relacionáveis a ele. Para Morris (1995), o signo pode ter aspectos universais, separando os diversos componentes e percebendo suas relações.

Sanches (2017), indicou que ao designer cabe a investigação de códigos socioculturais e estéticos, no contexto e de conteúdo de moda, o universo do usuário, o universo corporativo e produtivo, os parâmetros da interface do produto, sua utilidade, adaptação, percepção e comunicação, conceitos e detalhes de configuração o produto e a experimentação tangível e intangível das interfaces.

Sabendo da complexidade que está envolta na relação entre o ser humano e os artefatos, aprofundada, conforme Scoz et al. (2019), nos objetos do vestuário, e observando a complexidade envolta no processo criativo, apontada por Sanches (2017), a proposta dessa pesquisa originou-se da necessidade de compreender como, e se, os designers de moda conheciam e utilizavam algum método sistematizado para o reconhecimento de signos, que pudesse auxiliar para aumentar a assertividade, ou velocidade, do processo de desenvolvimento de produtos. A proposta foi de estudar a existência e utilização de métodos de reconhecimento de signos, por designer de moda, para compreender se na execução do processo criativo, havia alguma forma reconhecida de compreender e relacionar os signos atribuídos pelo consumidor aos artefatos, pelo qual o designer conseguisse sistematizar a ação de interpretação, durante seu processo criativo para desenvolver novos produtos. 
Para tal, foi aplicado um questionário a cinco designers de moda de diferentes cidades de Santa Catarina, de diferentes profissões do design de moda. Por meio dele era esperado identificar a existência e uso de métodos de reconhecimento de signos, durante o processo criativo, no âmbito do sistema de significação feito pelo ser humano. Sobre os dados gerados do questionário foram aplicados métodos de análise documental de Bardin (2016). Essa análise buscou evidenciar de forma sintética, as informações trazidas pelos respondentes.

Durante a pesquisa, os resultados indicaram que, para os designers respondentes, um método sistematizado de reconhecimento de signos é importante no processo de design. Um método de interpretação da linguagem semiótica indicou ser auxílio para aumento da assertividade na interpretação do designer, bem como redução do tempo de processo, como um importante auxílio para decodificação, codificação e interpretação de informações subjetivas. E, mesmo dispondo de diversas ferramentas para desenvolvimento da criatividade, e métodos de design para o desenvolvimento de produtos, que englobam um extenso repertório de pesquisas, os respondentes afirmaram não conhecer um método específico para reconhecer signos, dispondo, e reorganizando os métodos do design para suas necessidades.

A pesquisa foi dividida de forma a apresentar a pesquisa teórica de embasamento para o tema, na sessão 2, e sequencialmente os dados obtidos pelo questionário, a análise dos dados e as considerações finais.

\section{RECONHECIMENTO DE SIGNOS NO DESIGN DE MODA}

O design industrial, compreendido por suas características projetuais, pode utilizar-se do material cultural, o que possibilita ao designer abranger o valor simbólico dos produtos que cria. Os signos culturalmente compreendidos, que são atribuídos aos objetos do vestuário, e a seus atributos estéticos, como linhas, cores, formas, texturas e materiais, por exemplo, são objetos de estudo do designer. Esses elementos, ao correlacionarem-se com os signos, formam-se enquanto linguagem semiótica. 
Para Santos (2009, p.47) o "design industrial faz uso da semiótica para entender melhor as possíveis relações comunicativas entre os usuários e o produto". Sem essa compreensão, a criação torna-se um passo vazio no processo de desenvolvimento de um produto. A semiótica, no entanto, não consagra um método.

Segundo Scoz et al. (2019), a roupa iniciou uma trajetória de significação a partir do paleolítico, sendo dada a ela as funções de manter o pudor, proteger os corpos, e adornar para diferenciar. Durante os séculos a roupa foi valorada de diferentes formas, assumindo papel comunicativo.

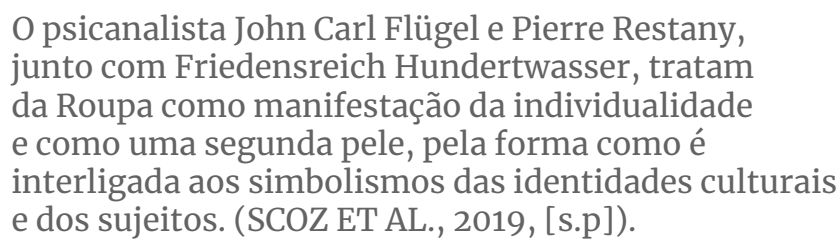

Tomando a roupa, que é parte do vestuário, para exemplificar o que ocorre no processo criativo durante o desenvolvimento de produtos no design de moda, analisou-se que, além de suas funções práticas, possui as funções simbólica e estética, significantes. Por ser a roupa, e outros objetos de estudo da moda, condutores de mensagens, a moda há muito é reconhecida como linguagem. Barthes (1978) descreveu a moda como uma linguagem semiótica. Para Sant'Anna (2016, p. 63), a moda impõe-se também sobre os objetos, que são "tanto expressão como construtores dos espaços, da temporalidade e conjuntamente dos sujeitos", sendo um sistema que, dentre as informações econômicas e produtivas, incorpora as informações culturais.

Para Hall (2016), a roupa pode ser vista com um objeto cujos signos atribuídos indicam identidades. Isso porque, no processo de significação dos objetos do vestuário, à roupa são inseridas informações do sujeito sobre si, e sua relação com o seu contexto. o que torna o processo criativo complexo, pois o usuário “cria uma imagem para representar e se en- 
volver com objetos de profundo significado particular. Num exercício pleno de comunicação visual, embute os preceitos do tempo (valores e signos), e de tamanho envolvimento se apega profundamente". (SCOZ ET AL., 2019, [S.P].).

Assim, ao processo criativo, incidem também identidades, que ocorrem na individualidade e se reconhecem no coletivo. Há relação próximo entre esses símbolos culturalmente consolidados, e a estética atribuída aos produtos, Mukarovski (2002), afirmou que a função estética e simbólica advém uma da outra.

Oliveira (2007, p.53), a respeito da leitura de composições visuais, afirma que as roupas possuem, "além da função semiótica, que sempre tiveram", a função de "expressar ideias e conceitos". Essa expressão pode ser compreendida nos signos. Ainda, para Oliveira (2007, p.37), "não se concebeu um método de alfabetização visual como existem métodos destinados ao ensino do que é escrito e transmitido pela linguagem verbal". Com isso compreende-se não haver uma metodologia unificada para compreensão dos signos que são atribuídos aos objetos do vestuário, ou seus elementos constitutivos, como "repetições, rebatimentos, contrastes" (OLIVEIRA, 2007, p. 27), ou cor, forma e textura.

O design de moda surgiu a partir de 2004, com a Resolução n. 5, de 8 de março de 2004, que inseriu a Moda nas diretrizes curriculares do design, a partir do qual a Moda foi legitimada como campo do design no Brasil. Dessa união, não só muitos cursos de moda se transformaram em cursos de design de moda (SCOZ, 2019), como muitos cursos de moda passaram a utilizar os métodos do design. Segundo Bürdek (2002), a partir de 1980 o design como método pautou-se na metáfora histórica, analisando objetos anteriores, na metáfora técnica, aplicando ciência e tecnologia, e na metáfora natural, a partir das formas, movimentos e acontecimentos naturais, como sociais. A partir da interpretação do designer as informações pesquisadas eram transferidas para o objeto criado, por transferência semântica (BÜRDEK, 2002), convertendo sentidos, significados, sentimentos em formas. 
Para Mozota, Klöpsch e Costa (2011), o processo do design pode seguir diferentes fases, sendo um processo dinâmico, em que as fases podem ser acessadas simultaneamente, ou aleatoriamente, conforme a necessidade. Consiste na habilidade técnica que, na fase criativa, conta com algumas ações, como a investigação do problema, pesquisa, exploração de alternativas, desenvolvimento de alternativas e realização do produto. Especificamente sobre o processo de design na moda, para Sanches (2017), é foco de atenção do designer contextualizar e identificar as demandas, especificar diretrizes, conceituar e experimentar conexões entre artefato e usuário, depurar a eficácia das interações, e consolidar alternativas para a demanda. As categorias de pensamento do designer, para a autora, seguem a identificação, expressão, compreensão e avaliação e um problema, a exteriorização de ideias, o deslocamento de pensamento e conexão de ideias, em que o designer julga e decide, como supervisiona a própria conduta.

Este trabalho mostra-se um exercício de escolhas, que só é possível com a busca por informações do produto, mercado e consumidor, das diversas áreas da vida do universo do produto e do consumidor (MORAES, 2010). O designer, sem abranger-se de informação, não possui caminho válido para compreender os signos que são dados aos objetos.

Bona (2019), ao entrevistar equipes de desenvolvimento de produto de micro e pequenas empresas do campo da moda, constatou que nenhum de seus entrevistados utilizava um método específico para criação de produtos, tendo desenvolvido método próprio, que se adequasse as necessidades do processo de design. Incorporando, ao desenvolvimento de novos produtos, a constância de pesquisa e a análise dos itens mais vendidos.

Santos (2009), destacou a importância de procedimentos sistemáticos, e enfatizou a importância de métodos sistematizados para agregar as funções de linguagem do produto, enfatizou a importância das decisões tomadas no início do processo de desenvolvimento de produtos, sendo nessa fase 
que são definidos o tempo e custo de produção, como a assertividade na comunicação do produto com o consumidor.

A partir do proposto, percebeu-se a existência de vasta metodologia de design de produto, aplicada ao universo de pesquisa e desenvolvimento de produtos de moda, como, igualmente, a criação de novas perspectivas de design, demonstrando ser o processo de design algo plástico e que necessita ser adequado as necessidades de cada produto e empresa. Sendo, parte indispensável do processo de design, a busca por informações e a interpretação delas, para então transformar atributos intangíveis em elementos tangíveis no produto, seguindo uma função prática, estética e simbólica. Sem haver uma metodologia que auxilie o processo interpretativo do designer, para considerações culturais, como os signos, em suas relações diacrônica e anacrônica em seu contexto social e com o usuário.

Nessa pesquisa, admitiu-se que, para o designer, há acúmulo de informações e, mesmo seguindo um método sistematizado para o design do produto, momento em que é possível utilizar diversas ferramentas para geração criativa, como braingstorming, por exemplo, não foi encontrado um método sistematizado que o auxiliasse na compreensão dos signos que o consumidor atribui aos objetos. Cabendo, exclusivamente a interpretação do designer sobre a informação pesquisada, decodificar e codificar os atributos sensoriais e sensíveis.

A partir das fontes teóricas estudadas, observando a importância dessa fase inicial do processo de design, e a inexistência teórica de um método específico para auxiliar o designer na compreensão de signos culturais, que decidiu-se compreender se designers de moda de Santa Catarina utilizavam algum método para o reconhecimento e compreensão de signos, quais seriam e como seria seu processo no desenvolvimento de produtos. A metodologia e descrição do questionário serão apresentados na próxima sessão. 


\section{METODOLOGIA: DESCRIÇÃO DO QUESTIONÁRIO APLICADO}

A aplicação do questionário objetivou descobrir se haveria métodos já compreendidos e utilizados por designers de moda, relacionados diretamente a compreensão dos signos do vestuário, e quais seriam estes métodos. Foram selecionados cinco participantes para a pesquisa, estes participantes possuem formação em design de moda e trabalham em áreas distintas da moda, que utilizam o processo criativo no desenvolvimento de suas atividades laborais.

Após a escolha dos cinco profissionais para esta pesquisa, foi feito o contato com cada um deles por meio de mídias virtuais, e-mail e WhatsApp. A cada um deles foi solicitada a participação, e a possibilidade de uso do material de pesquisa para este artigo, a partir do aceite de cada um, o questionário foi enviado pelas mesmas mídias de contato, no formato google forms. Este contato ocorreu em novembro de 2020.

Para manter o sigilo dos dados pessoais, foi atribuído um pseudônimo para cada participante. O primeiro respondente será chamado de R1, e após este estão R2, R3, R4 e R5. Os dados obtidos no questionário serão apresentados conforme a sequência de perguntas e respostas.

Para os cinco participantes foram aplicados cinco questionamentos. Na Figura 1, a seguir, foram apresentados os respondentes, questionamentos aplicados e uma caracterização inicial da formação e área de atuação dos respondentes.

Pela área de atuação de cada respondente, compreendeu-se que há, dentro de suas ações profissionais, necessidade de uso de métodos para compreensão dos signos dos produtos e seus elementos estéticos.

O R1, na docência do Ensino Superior, e na produção de moda, sintetiza as informações para exemplificar aos estudantes, e para montagem de produções para filme, fotografia, vitrine etc. $\mathrm{O}$ respondente $\mathrm{R} 2$, na consultoria e pesquisa de moda, necessita compreender as informações culturais, contextos, e suas relações, nos diversos consumidores e mercados para os 
1. Descreva sua formação na área do design e da moda, e qual sua principal atividade.

2. Você utiliza ou aprendeu algum método sistematizado que auxilie na identificação dos significados culturais que são dados aos objetos e seus elementos visuais?

3. Diga o nome do método utilizado, caso seja um método reconhecido.

4. Descreva a forma como interpreta os signos, e seus elementos visuais componentes. Descreva os passos seguidos para interpretar e aplicar significados já existentes nos produtos a ser criados. 5. Você sente falta de pesquisas que identifiquem os significados que as pessoas dão aos objetos do vestuário?

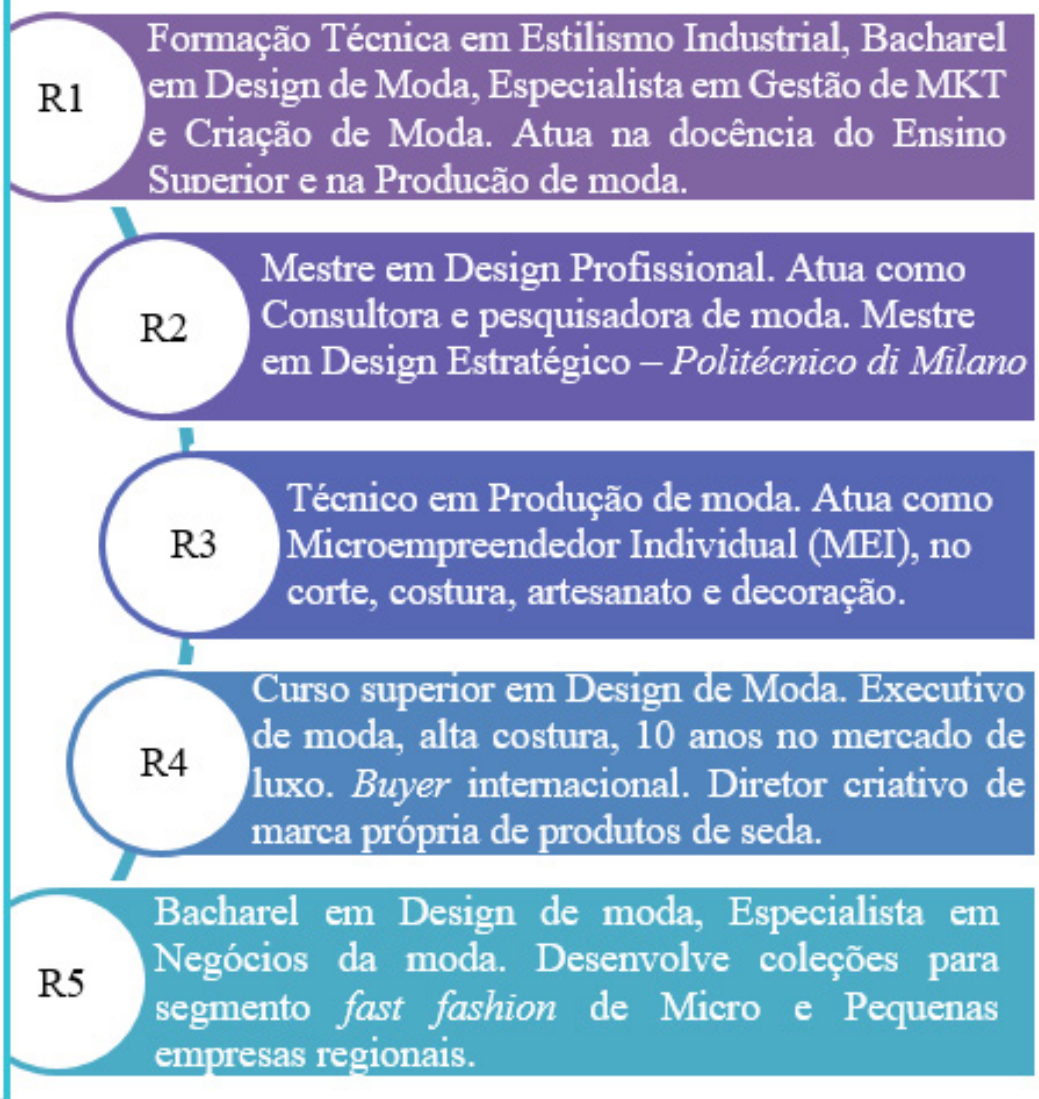

Figura 1: questionamentos, pseudônimos e caracterização dos respondentes. Fonte: Dados do questionário compilados pelos autores.

quais elabora seus materiais de consulta. O respondente R3, como MEl artesã, utiliza um método de criação, o respondente R4 necessita compreender os signos do contexto de luxo, e efetuar compras de insumos, materiais, aviamentos, mesmo elaborar coleções, dirigir processo criativo, analisar efeito simbólico e estético dos produtos da marca que dirige, além dos atributos físicos para o consumidor. O R5, atuando diretamente na coleção de produtos para fast fashion, participa da rapidez das subcoleções e novidades constantes do mercado de moda.

Os respondentes representam, cada um, uma área de atuação do campo da moda, que efetuam ações criativas e utilizam métodos do processo de design. A seguir, serão apresentados os dados e a análise documental aplicada sobre os dados do questionário. 


\section{RESULTADOS: APRESENTAÇÃO DE DADOS DO QUESTIONÁRIO}

Os respondentes foram questionados se utilizavam, conheciam ou aprenderam algum método sistematizado que os auxiliasse na identificação dos significados culturais que são dados aos objetos e elementos visuais. Como significados culturais, compreendem-se as relações do usuário com o produto em seu contexto vivido.

Scoz et al. (2019), indicou que, significações atuais como a saia foi designada ao feminino, e a calça ao masculino, ocorreram ainda no século $\mathrm{XI}$, perpassadas culturalmente pela linguagem. Devido ao fator de diferenciação, necessidade agregada a vestimenta na relação do consumidor com o produto, aos burgueses da Revolução Industrial, no século XIX, foi atribuída preto, cortes retos, tecidos práticos, num contexto que os fazia o oposto da aristocracia. Na vestimenta sóbria do burguês novas configurações de trajes foram elaboradas, para novas necessidades, como o smoking (SCOZ ET $A L ., 2019)$. Vestes que, durante o século $X X$, representaram o homem sério, nos ideais de trabalho do positivismo. Signos que seguiram os produtos, e seus elementos constituintes (cores, formas, texturas, modelagens, padronagens, cortes, materiais, aviamentos etc.), por todo o século $X X$.

Para Scoz et al. (2019, [s.p.]), "a minissaia do século XX, tão comum na atualidade, não existiu antes dos anos 1960. Período marcado pelo feminismo e juventude. Os ideais se modificam, alguns ficam no passado, outros surgem como novidade", a minissaia continuou por muito tempo reconhecida como uma vestimenta jovem, imprópria para mulheres mais velhas. À medida que os papéis sociais sofrem alterações, os signos de impróprio e exclusivo se perderam para a consumidora com mais de 30 anos, mas os signos de liberdade e jovialidade, mesmo ressignificados, continuaram parte da minissaia no vestuário das mulheres jovens, adentrando o vestuário infantil. 
Determinadas tradições, como cores brancas para noivas, e ternos pretos, azuis ou cinzas para noivos, perpassam culturalmente, por meio da linguagem semiótica, signos passados, que se caracterizam diferentemente para cada consumidor em seu contexto. E, mesmo sem que a tradição tenha uma relação direta com o público, o vestuário tradicional segue sendo assimilado para as necessidades do usuário.

Nos casos descritos, as vestes masculinas, a minissaia, e a tradição do casamento, os signos necessitam ser interpretados, para que os atributos tangíveis a que eles foram atribuídos possam ser codificados para públicos diversos. Possibilitando, como já foi efetuado, o smoking feminino, trajes de casamento para união estável homoafetiva e, por que não, minissaia masculina.

Nos questionamentos aplicados, três dos cinco profissionais conheciam e aplicavam métodos sistematizados para identificação de signos atribuídos a objetos. Buscou-se, pelas respostas, conhecer quem foram os respondentes que afirmaram conhecer, para melhor relacionar esta resposta com a formação acadêmica e profissional.

Os dois profissionais que indicaram desconhecer métodos são R1 e R4, que atuam, respectivamente, com docência e com segmento luxo. Estas respostas demonstram a dificuldade em encontrar métodos específicos sobre signos culturais, para lecionar moda, e para atividades criativas conceituais, como as do mercado do luxo.

Já os três profissionais que afirmaram conhecer métodos sistematizados para identificação de signos foram R2, R3 e R5. Que são, respectivamente a consultora de moda, a microempreendedora da economia criativa e o respondente designer de moda que atende o segmento fast fashion.

Esta resposta indica possibilidade de haver um método sistematizado, mas ainda necessitou-se compreender se este método era reconhecido, próprio, e como era feito aplicação deles.

Para melhor compreender estas respostas, questionou-se qual era o nome do método utilizado. Na Figura 2 foram compiladas o nome do método, e a descrição de execução dos três participantes que afirmaram utilizar um método. 


\section{R1 Design Estratégico do Politécnico di Milano}

Método do design próprio, na abordagem sistêmica do processo do design voltado a inovação, sendo design, protótipo, interação e pesquisa os quatro aportes básicos do método.

\section{R3 Pesquisa de moda e tendência}

Parte da metodologia do design, que ocorre no processo do desenvolvimento de produtos, auxilia no processo criativo na busca de informações diversas, e na análise de tendências de moda de publicações específicas.

\section{R5 Método Próprio}

Pesquisa cultural, ideográfica, pesquisa do local para onde se destina o produto ou serviço

Figura 2: métodos de reconhecimento de signos descritos pelos respondentes. Fonte: Dados do questionário compilados pelos autores.

A Figura 2 demonstrou não haver uma nomenclatura própria para o método descrito pelos respondentes. Ainda, a questão solicitava que indicassem um método de reconhecimento de signos, e no lugar desse os respondentes indicaram partes do método processual do design. Compreendeu-se, portanto, que mesmo para os respondentes que indicaram utilizar um método de reconhecimento de signos, o que houve foi o uso de métodos tradicionais do design, mesmo o design estratégico, alinhados as suas necessidades profissionais. Não havendo um método específico, e reconhecido, para auxílio na interpretação simbólica das informações de pesquisa.

Compreendeu-se que, o que os respondentes indicaram como um método específico para reconhecimento de signos é, na verdade, parte do processo de desenvolvimento de produto (PDP), nas fases iniciais do design. para tal, buscou-se em Panizza (2004) e Montemezzo (2003), reconhecer as fases do PDP.

A Figura 3 apresenta as fases iniciais do processo de design, a fase analítica e a fase decisiva, na lateral esquerda, e acima, as fases do PDP. Em cada fase, foram inseridas as ações descritas pelos respondentes como passo a passo do seu método de reconhecimento de signos. 
Fase 1:

Planejamento

Fase 2:

pesq. de público

e mercado
Fase 3:

relação

usuário $\mathrm{x}$ produto
Fase 4:

delimitações

conceituais
Fase 5: geração de alternativas
Fase 6: elaboração e realização do produto

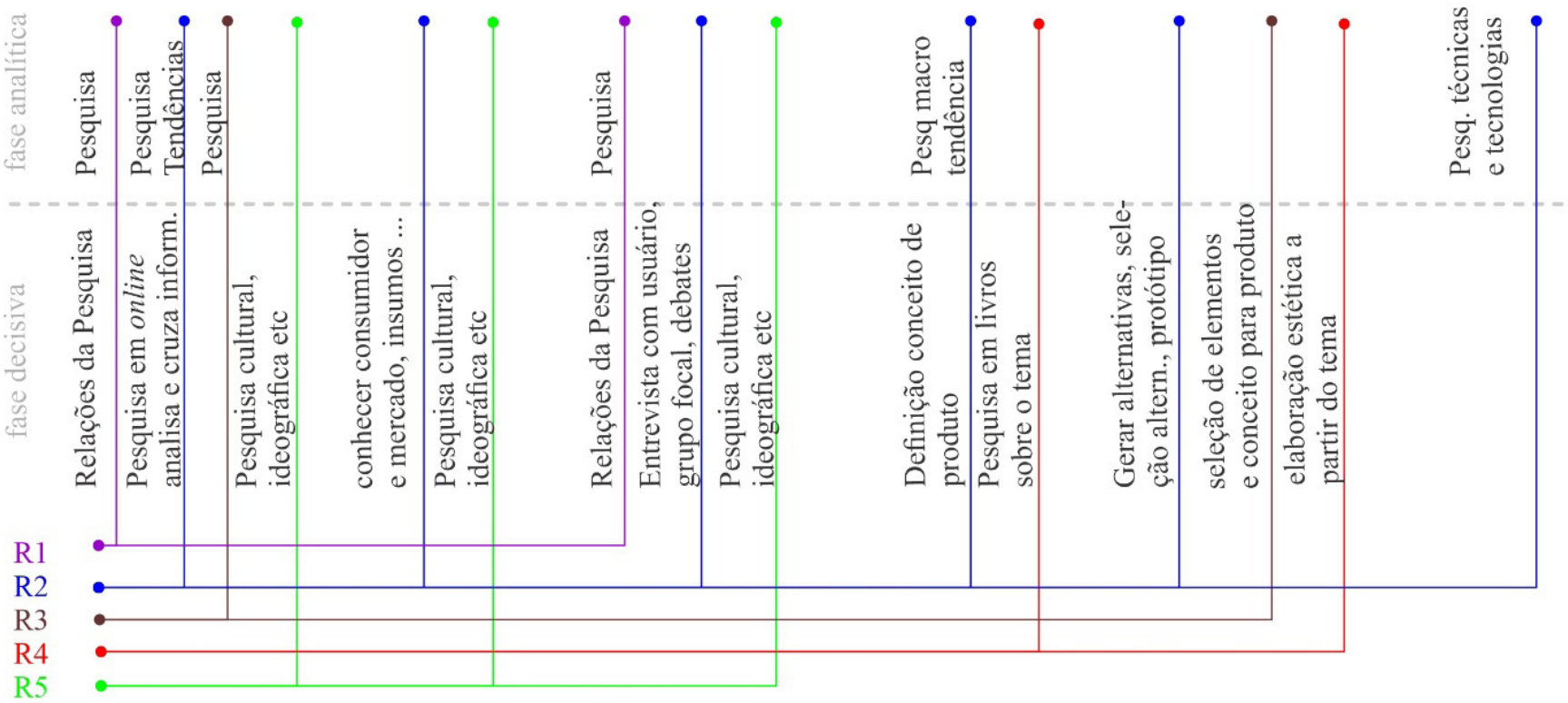

Figura 3: descrição do método de reconhecimento de signos pelos respondentes. Fonte: Elaborado pelos autores a partir do questionário, de Panizza (2004) e Montemezzo (2003).

Em análise da Figura 3, percebe-se inicialmente que todas as ações descritas pelos respondentes é parte das fases iniciais do processo de design, as fases analítica e decisiva, que concentram, consecutivamente, as pesquisas, e a escoIha de elementos a partir da interpretação do designer sobre as pesquisas para a geração de alternativas.

As fases do PDP concentram-se nas fases iniciais do design, seguindo, no sexto passo, para a fase produtiva do design. Foi visto que apenas o R2 indicou pensar na fase produtiva, já nas fases iniciais do design. isso pode indicar que durante a geração de alternativas, o designer pode utilizar essas informações, sem de fato, efetuar uma análise sobre.

Pode-se perceber que todos os respondentes utilizam o PDP, em momentos distintos de suas ações de trabalho, sem uma ordem específica, mas como um método de auxílio na execução do design. Montemezzo (2003), e Panizza (2004), definiram o PDP como um método que não é rígido, podendo ser adequado às necessidades de cada designer e empresa. 
Os respondentes R1 e R4 afirmaram não conhecer um método específico para a compreensão de signos do vestuário, R1 afirmou executar a interpretação de "maneira muito empírica," e R4 indicou que dá "enfoque ao significado cultural já existente" ou amplia e dá "novos conceitos reverberados na atualidade, provocando assim uma nova forma de pensar e questionar os significados culturais definidos". O método descrito e utilizado pelos participantes R1 e R4 regem a forma de trabalho do designer de moda, instruindo a primeiro conhecer seu público, então conhecer o mercado, e estudar e compreender tendências de moda e são partes constituintes do PDP.

O respondente R1 afirmou fazer pesquisa e relações, para busca de informações para desenvolvimento de produto, nesse sentido, pode-se compreender que as etapas analítica e decisiva ocorrem simultaneamente, buscando conhecer consumidor, mercado, tendências, e relacionando as informações obtidas com o usuário.

O respondente $\mathrm{R} 4$, indicou que seu primeiro passo é uma pesquisa profunda em livros sobre o tema a que pretende trabalhar, nesse sentido, compreende-se que a fase analítica e decisiva, igualmente, ocorrem simultaneamente, uma vez que a pesquisa de referências estéticas e simbólicas ocorre após a escolha de um tema. E para tal, é importante já reconhecer o consumidor. Num segundo momento, R4 desenvolve estampas com elementos de inspiração, a partir da interpretação das informações de pesquisa. A impressão obtida, da fala de R4, foi que a interpretação das informações ocorre de forma natural, sem uso de quaisquer ferramentas específicas para auxílio da decodificação dos dados simbólicos.

O respondente R2 descreveu doze passos de execução, como forma de reconhecimento dos signos, com uso do método de design politécnico di milano. Foi percebido que os passos descritos fazem parte do PDP, nas fases iniciais do design, tendo modificado a ordem de execução do método para suas necessidades. R2 identificou que executa pesquisa de tendências para o design em geral, efetuando pesquisa 
em revistas online, sites, blogs, e com influenciadores digitais, pesquisa de campo, na rua, em feitas entre outros, efetuando uma análise geral e o cruzamento das informações de pesquisa. Essas ações fazem parte da primeira fase do PDP de Montemezzo (2003), e Panizza (2004), e são parte das fases iniciais do design, na fase analítica e decisiva.

Ainda, o respondente afirmou executar uma pesquisa para conhecer o mercado, os clientes, concorrentes, fornecedores e produtos, e então aprofundar o conhecimento sobre o usuário, em seu comportamento, hábitos, estilo de vida etc. Para o respondente, é importante entrevistar os usuários, ou grupos, para promover debates. Essa afirmativa levou a compreender que é a partir do consumidor que surgem os conceitos atribuídos aos objetos e seus elementos visuais. $O$ grupo focal, uso de questionários e entrevistas são ferramentas úteis para o reconhecimento de signos de produtos de moda. embora sejam executados metodologicamente, não se pode afirmar que sejam um método de auxilio para interpretação das informações codificadas ao longo da pesquisa, para além do consumidor.

O respondente R3 afirmou executar pesquisa, e o respondente R5 afirmou executar pesquisa cultural, ideográfica, dentre outras, o que sugere já ter conhecimento de público, por exemplo, ou executar a busca de informações de forma simultânea, efetuando as interpretações ao longo da pesquisa, tomando decisões enquanto analisa as informações, inclusive, tomando decisões acerca de quais informações buscar.

$\mathrm{Na}$ busca por conceitos de pesquisa, R4 executa pesquisa de macrotendência, buscando identificar a evolução das filosofias de vida das pessoas, bem como suas atitudes e comportamentos dentro da sociedade em geral, para então efetuar a definição do conceito de produto, esse último processo ocorre a partir da interpretação que ele faz de todo material coletado até então. Demonstrando ser, o reconhecimento de signos, um processo de busca e escolha, que depende unicamente do designer, utilizando o design como um método. 
R2 executa a pesquisa de técnicas e tecnologias que possam ser interessantes para o projeto, essa ação descrita é a fase 6 do PDP, no entanto, o respondente afirmou executá-la durante a fase analítica. E é, com o conceito do briefing, do produto, e com auxílio da empresa que contratou a consultoria, que são feitas as escolhas finais das alternativas de produto mais viáveis e interessantes.

$\mathrm{O}$ respondente $\mathrm{R} 5$ afirmou executar pesquisa do local para onde o produto ou serviço se destina, durante a fase analítica, correlacionando-se a fase 3 do PDP. Já R3 afirmou que efetua a seleção de cores e conceitos que melhor se adaptam a proposta de produto, principalmente cores. As afirmativas corroboram que os respondentes, na verdade, estão utilizando métodos do próprio processo de design, em suas fases iniciais. Efetuando a busca por informações, e a interpretação, inerente ao designer, para a compreensão de conceitos, seleção de cores, aviamentos, materiais etc., que melhor se adaptam as necessidades do produto, marca, processo produtivo, custos, viabilidade e público.

É possível que os métodos utilizados pelos respondentes auxiliem a compreender como indivíduos interagem com objetos significantes, que utilizam no seu cotidiano, mas ainda não representam um método específico para o reconhecimento dos signos.

Os métodos sistematizados a que se propôs compreender existência, fazem menção a diretrizes semânticas e indicações dos signos atribuídos, suas relações entre si, e com o contexto, ou significados existentes dados aos objetos em determinada construção identitária de forma a auxiliar a interpretação do designer. As respostas, apesar de não concordarem quanto ao uso ou não de um método, foram muito parecidas nas suas descrições. Todas passaram por fases de pesquisa, utilizaram pesquisa com consumidor, mercado, tendência de consumo, moda, sociedade, executando análise e interpretação de dados pesquisados. 
Por meio dos métodos descritos pelos participantes, depois de determinado tempo de profissão, um profissional pode compreender que determinados elementos indicam feminino ou masculino, ou um conceito histórico, de belo e feio ou atribuições sensíveis, por exemplo, a partir de uma densa pesquisa histórica. Já para um designer iniciante, ou para estudantes, essa compreensão se tornaria mais difícil. Ainda assim, os passos descritos são amplos, e não garantem que o designer vá, de fato, compreender se determinado objeto tem um valor de status para determinado gênero, ou para determinados indivíduos em idade específica, apenas que ele fará escolhas acerca disso.

A última pergunta feita aos participantes foi se sentiam falta de pesquisas que identificassem os significados que as pessoas dão aos objetos do vestuário. Quatro respondentes disseram que sim, e um respondente afirmou que não sentia falta. Indica que maior parte dos profissionais entrevistados necessita de diretrizes específicas acerca do signo.

Para compreender a resposta negativa, buscou-se pelo respondente em questão. A resposta foi obtida do respondente R2 que é, justamente, a profissional que trabalha com pesquisa de tendência e consultoria de criação. Compreendeu-se aqui que a resposta de R2 se justificou, pois, possui prática nas atividades que se referem as significações culturais, não só pela formação específica descrita, mas também pelo tempo de atividade profissional.

Os resultados obtidos trouxeram claras informações acerca da necessidade de pesquisas que relacionem diretrizes para compreensão das informações significantes dadas aos objetos e elementos visuais de produtos de moda, como os do vestuário. A formação acadêmica e profissional dos respondentes revelou que não são iniciantes, ainda assim, desconhecem métodos sistematizados específicos, que não os de desenvolvimento de produto.

Os métodos indicados foram muito parecidos, e todos indicaram a necessidade de busca de informação e das escolhas que fazem parte do universo do trabalho do designer. Reco- 
nhecer signos já existentes não retira a necessidade de tais escolhas, mas sim auxiliar na assertividade delas. Portanto, espera-se que esta pesquisa possa indicar a necessidade de tais pesquisas na área do design, em específico do design de moda.

\section{CONSIDERAÇõES FINAIS}

Ao início desta pesquisa era esperado indicar os métodos de reconhecimento dos signos culturais atribuídos ao vestuário, utilizados por designers de moda. $O$ estudo revelou que, para os participantes da pesquisa, o processo criativo é complexo e rege-se por muitos passos de pesquisa. Esses passos foram compreendidos por alguns como um método sistematizado para compreensão de signos. O que, em si, já denota que há falta de pesquisas, conteúdos e métodos próprios sobre o tema.

Ao fim, maior parte dos entrevistados indicou interesse em pesquisas que descortinem os significados dados a cada elemento visual que compõe um objeto do vestuário, e atribuam diretrizes para a criação de produtos utilizando suas informações. Compreendeu-se que um método dessa forma poderia facilitar o processo criativo. E, conforme a citação de Oliveira (2007), poderia ser identificado como uma forma de ensinar a ler significantes e significados.

Esta pesquisa indicou que o processo de pesquisa para desenvolvimento de coleção é uma busca por informações, num processo relativamente longo que depende de muitas escolhas do designer, para além de suas decisões criativas. Compreende a forma como ele irá interpretar a pesquisa feita. O uso de um método poderia diminuir o tempo atribuído ao processo de criar objetos, e aumentar a assertividade. Um método sistematizado não iria absolver o profissional de fazer suas escolhas, mas estas não seriam atreladas ao que cada um pensa de determinado dado cultural. O processo poderia ser menos subjetivo, o que melhora não só a atividade profissional, mas a atividade do professor ao lecionar conteúdos relativos à compreensão de signos. 
A escolha dos participantes da pesquisa buscou por profissionais das diferentes fases da criação do produto, desde o ensino do tema, até o desenvolvimento e a consultoria, os profissionais indicaram trabalhar em ramos criativos diferentes, e obtiveram formações em moda e design. Ainda assim, suas respostas mostraram-se muito parecidas acerca da forma como efetuam criação. O que denota que a pesquisa de mercado, público-alvo e tendência ainda é o método mais assertivo para compreender o consumidor e seus interesses. Dependendo desta compreensão, toda a criação de produtos.

Do luxo ao fast fashion, nas instituições de ensino e empresas, o mesmo método de criação vem sendo repetido e difundido. É esperado, portanto, que a pesquisa aqui apresentada conduza a mais experimentos que possam ampliar as possibilidades dentro do processo de criação dos produtos, que ampliem os métodos possíveis para compreensão dos signos que são atribuídos aos objetos do vestuário.

\section{REFERÊNCIAS}

BARDIN, Laurence. Análise de Conteúdo. 3.

Reimpressão. São Paulo: Edições 70, 2016. 277 p.

BARTHES, Roland. 0 grão da voz. São

Paulo: Edições 70, 1981. v. 37.

BARTHES, Roland. O sistema da moda.

Gustavo Gil: Barcelona, 1978. 270 p.

BONA, Sheila Fernanda. Método de projeto de coleção

em design de moda: uma configuração para micro e pequenas empresas. 2019. 138 f. Dissertação (Mestrado)

- Curso de Curso de Mestrado do Programa de Pós-

Graduação em Moda, Área de Concentração Design e Tecnologia do Vestuário, Ceart, Universidade do Estado de Santa Catarina, Florianópolis, 2019. Disponível em: https://bit.ly/3mJjmKT. Acesso em: 11 ago. 2021. 
BÜRDEK, Bernhard E. Diseño. Historia, teoría y práctica del diseño industrial. $3^{\mathrm{a}}$ ed. Barcelona: Editorial Gustavo Gil S.A., 2002.

GOMES FILHO, João. Gestalt do objeto. Sistema de leitura visual da forma. 8a ed. São Paulo: Escrituras, 2008.

GREIMAS, Algirdas Julius. Semiótica figurativa e semiótica plástica. Significação, n.4, julho de 1984.

HALL, Stuart. Cultura e representação. Rio de Janeiro: Editora APICURI / PUC-Rio, 2016. 219 p.

HESKETT, John. Design. A very short introduction. New York: Oxford University Press, 2002.

LÖBACH, Bernd. Industrial design. Bases para configuração dos produtos industriais. Tradução de Freddy Van Camp. São Paulo: Edgar Blücher, 2001.

MONTEMEZZO, Maria Celeste de Fátima Sanches.

Diretrizes metodológicas para o projeto de produtos de moda no âmbito acadêmico. Bauru: UNESP, 2003.

Dissertação de Mestrado, Faculdade de Arquitetura, Artes e Comunicação, Universidade Estadual Paulista, 2003. 98fls.

MORAES, Dijon De. Metaprojeto: o design do design. São Paulo: Blucher, 2010.

MORRIS, Charles. Fundamentos de la teoria de los signos. Tradução de Rafael Grasa. Buenos Aires: Paidós, 1995.

MOZOTA, Borja; Brigitte; KLÖPSCH, Cássia; COSTA, Filipe Campelo Xavier da.

Gestão do design: usando o design para construir valor de marca e inovação corporativa. Porto Alegre: Bookman, 2011.

MUKAROVSKI, Jan. Signo, funcion y valor. Estética

y semiótica del arte de Jan Mukarovski. Tradução de Jarmila Jandová e Emil Volek. Bogotá: Plaza \& Janés Editores Colombia S.A., 2000. 
NORMAN, Donald A. 0 design do dia a dia. Tradução

de Ana Deiró. São Paulo: Rocco, 2006.

OLIVEIRA, Sandra Ramalho. Moda também é

texto. São Paulo: Edições Rosari, 2007. 134 p.

PANIZZA, Janaína Fuentes. Metodologia e processo criativo

de projetos em comunicação visual. São Paulo: USP,

2004. Dissertação de Mestrado, Escola de Comunicação e

Artes, Universidade do Estado de São Paulo, 2004. $254 \mathrm{fls.}$

SANCHES, Maria Celeste de Fátima. Moda e

projeto: estratégias metodológicas em Design. São

Paulo: Estação das letras e Cores, 2017.

SANTAELLA, Lucia; NÖTH, Winfried. A linguagem das mercadorias.

Revista signos do consumo, v.1, n.1, 2009, p.21-43.

SANT'ANNA, Mara Rubia. Teoria De Moda:

SOCIEDADE, IMAGEM E CONSUMO. São Paulo:

Estação das letras e cores, 2016. 106 p.

SANTOS, Celio Teodorico. Requisitos de linguagem do produto: uma proposta de estruturação para as fases iniciais do PDP. Florianópolis: UFSC, 2009. Tese de Doutorado, Universidade Federal de Santa Catarina, 2019. 205fls.

SCOZ, Emanuella. A Trajetória dos egressos (2001) do curso

de moda da FURB: Currículo e campo de atuação. 2019.

121fl. Dissertação (Mestrado em Educação) - Universidade

Regional de Blumenau, Blumenau, 2019. Disponível

em <https://bit.ly/3z8r2vc>. Acesso em 17.08.2021.

SCOZ, Emanuella et al. A ROUPA. A evolução da Roupa em sua Relação com a sociedade. Do ano 1000 d.C. até o século XX. 2ed. Blumenau: AmoLer, 2019. 166 p.

STERNBERG, Robert J. Psicologia cognitiva. Tradução da $5^{a}$ edição norte americana, por Anna Maria Dalle Luche e Roberto Galman. São Paulo: Cengage Learning, 2010. 